\title{
LII. On a method of discriminating real from accidental coincidences between the lines of different spectra
}

\section{Runge}

To cite this article: C. Runge (1890) LII. On a method of discriminating real from accidental coincidences between the lines of different spectra, Philosophical Magazine Series 5, 29:181, 462-466, DOI: $10.1080 / 14786449008619969$

To link to this article: http://dx.doi.org/10.1080/14786449008619969

曲 Published online: 08 May 2009.

Submit your article to this journal $[\pi$

Џll Article views: 2

Q View related articles $\sqsubset$ 
LII. On a Method of Discriminating Real from Accidental Coincidences between the Lines of Different Spectra. By C. Runge, Professor of Mathematics at the technische Hochschule, Hanover *

T $\mathrm{N}$ the Philosophical Magazine for January 1888 E. F. J. 1 Love gives a method of discriminating real from accidental coincidences between the lines of different spectra. The method is as follows:-The differences between the wave-lengths of the lines compared are arranged in groups, each group containing those observations the errors of which lie within certain narrow limits. The number of observations in each group is then plotted as an ordinate of a curve, the average error of the group being the abscissa. It seems allowable to assume that this curve will have the form of the curve given by the law of error $y=a e^{-c^{2} x^{2}}$ in case the coincidences are real and not merely accidental. Any serious divergence from the form of the latter curve will therefore indicate that the coincidences are accidental. So far, I think, one may agree with the author. But he argues further:-If the plotted curve resembles the curve given by the law of error, the coincidences are not accidental. I do not see the necessity to draw this conclusion. On the contrary, I am able to show that for a certain distribution of lines in one spectrum the plotted curve must always resemble the error curve for any lines that one pleases to take as lines of the other spectrum. Let $\lambda_{0}, \lambda_{1}, \ldots \lambda_{n}$ be the wave-lengths of any spectrum, $\lambda_{0}$ the smallest and $\lambda_{n}$ the largest. What then is the probability that an arbitrary number $\lambda$ between $\lambda_{0}$ and $\lambda_{n}$ does not differ by more than $x$ from the nearest of the wavelengths $\lambda_{0}, \lambda_{1}, \ldots \lambda_{n}$ ? To find this probability one must add together all the parts between $\lambda_{0}$ and $\lambda_{n}$ that differ by not more than $x$ from one of the numbers $\lambda_{0}, \lambda_{1} \ldots \lambda_{n}$. This sum divided by $\lambda_{n}-\lambda_{0}$ is equal to the probability in question. Let $d_{1}, d_{2} \ldots d_{n}$ signify the differences of two consecutive wavelengths in such order that $d_{1} \leqq d_{2} \leqq d_{3} \ldots \leqq d_{n}$, and let $d_{v+1}$ be the first of these quantities, that is not smaller than $2 x$, so that $d_{v}<2 x \leq d_{v+1}$. Then all the intervals $d_{1}, d_{2}, \ldots$ $d_{v}$ have to be included in the sum, whilst for each of the intervals $d_{v+1}, d_{v+2}, \ldots d_{n}$ only a part equal to $2 x$ has to be added. We find therefore the probability in question

* Communicated by the Author. 
equal to

$$
\frac{d_{1}+d_{2}+\ldots+d v+2(n-v) x}{\lambda_{n}-\lambda_{0}} \text {. }
$$

From this expression one may deduce a simpler one for the probability that the difference between the arbitrary number $\lambda$ and the nearest of the wave-lengths $\lambda_{0}, \lambda_{1} \ldots \lambda_{n}$ lies between $\frac{d_{v}}{2}$ and $\frac{d_{v+1}}{2}$, It is

$\frac{d_{1}+d_{2}+\ldots+d_{v}+(n-v) d_{v+1}}{\lambda_{n}-\lambda_{0}}-\frac{d_{1}+d_{2}+\ldots+d_{v-1}+(n-v+1) d_{v}}{\lambda_{n}-\lambda_{0}}$

or

$$
\frac{(n-v)\left(d_{v+1}-d_{n}\right)}{\lambda_{n}-\lambda_{0}}
$$

Let us take $\frac{d_{1}}{2}, \frac{d_{2}}{2} \ldots \frac{d_{n}}{2}$ as abscissas, and let us draw a rectangle over the interval $\frac{d_{v}}{2}$ to $\frac{d_{v+1}}{2}$ with $\frac{d_{v+1}-d_{v}}{2}$ as base and $2 \frac{n-v}{\lambda_{n}-\lambda_{0}}$ as height. Then the area of this rectangle will represent the probability, that the difference of $\lambda$ from the nearest wavelength lies between $\frac{d_{v}}{2}$ and $\frac{d_{v+1}}{2}$ (for $v=0$ write $d_{0}=0$ ). Thus we get what we may call a curve of difference analogous to the curve of error. The curve of difference forms the profile of a staircase, the steps of which may be of different height and depth. If $n$ is a large number and the seale of the drawing not too large, the staircase will resemble a smooth curve; and it may be seen from the following application that there are cases where it closely resembles the curve $y=\frac{2 c}{\sqrt{\pi}} e^{-c^{2} x^{2}}$, if one is allowed to choose the constant $c$ accordingly.

I have taken as an example the first five ultra-violet bands of the water-spectrum as observed by Liveing and Dewar*. They consist in 598 lines extending from 2268 to $3203 \cdot 5$.

* Phil. Trans, of the Roy. Soc. 1888. 
464 Prof. C. Runge on Real and Accidental Coincidences

\begin{tabular}{|c|c|c|c|c|c|}
\hline Abscissa. & Ordinate. & Abscissa. & Ordinate. & Abscissa. & Ordinate. \\
\hline 00 tó $\cdot 05$ & $1 \cdot 28$ & .90 to 95 & 35 & 1.85 to 1.90 & .05 \\
\hline$\cdot 05,10$ & 1.28 & $\cdot 95,1 \cdot 00$ & $\cdot 32$ & $1.90,2 \cdot 00$ & $\cdot 04$ \\
\hline -15, 10 & $1 \cdot 27$ & $1.00,1.05$ & .28 & $200,2 \cdot 05$ & .04 \\
\hline$\cdot 15 " .20$ & $1 \cdot 26$ & $1.05 " 1.10$ & .25 & $205,2 \div 10$ & .04 \\
\hline$\cdot 20, \cdot 25$ & 1.24 & $1 \cdot 10 \geqslant 1 \cdot 15$ & .23 & $2 \cdot 10,215$ & .08 \\
\hline $.25,30$ & $1 \cdot 18$ & $1 \cdot 15,1.20$ & .20 & 215,220 & $\cdot 03$ \\
\hline$\cdot 30,35$ & $1 \cdot 10$ & $1.20,1.25$ & $\cdot 18$ & $2 \cdot 20 \# 2 \cdot 25$ & .03 \\
\hline$\cdot 35,40$ & 1.02 & $1.25,1.30$ & $\cdot 15$ & $2 \cdot 25,230$ & $\cdot 02$ \\
\hline$\cdot 40 " .45$ & .96 & $1 \cdot 30,1.35$ & •13 & $2 \cdot 30,2 \cdot 35$ & .02 \\
\hline$\cdot 45,50$ & .90 & $1 \cdot 35,1.40$ & .11 & 235,250 & .02 \\
\hline .50 .55 & .82 & $1.40 " 1.45$ & .11 & $250-265$ & .02 \\
\hline $.55 " .60$ & .74 & $1.45 " 1.50$ & $\cdot 11$ & $2 \cdot 65,2 \cdot 80$ & .01 \\
\hline $.60-65$ & .67 & $1.50=1.55$ & .09 & 280,305 & .01 \\
\hline $65 " \cdot 70$ & 59 & $1.55 " 1.60$ & $\cdot 08$ & $3.05,3.35$ & .01 \\
\hline $.70 \quad 75$ & .57 & $1.60=1.65$ & .07 & $3 \cdot 35-3 \cdot 65$ & $\cdot 01$ \\
\hline 80. ". & .50 & $1.65,1.75$ & .06 & $3.65,3.80$ & .01 \\
\hline $.80 " .85$ & $\cdot 44$ & $1.75,1.80$ & .06 & $3 \cdot 80,570$ & .00 \\
\hline -95 & 39 & $1.80,1.85$ & $\cdot 05$ & $570 \leadsto 670$ & .00 \\
\hline
\end{tabular}

In order to compare these values with those given by the law of error, I have for the sake of simplicity interpolated the values of the ordinate for $x=0 \cdot 1,0 \cdot 2$, \&c., by taking the mean of the two neighbouring ordinates. The third column contains the ordinates of the curve $y=\frac{2 c}{\sqrt{\pi}} e^{-c^{2} x^{2}}$ for $c=1 \cdot 148$. The table shows the close agreement between the two curves.

\begin{tabular}{|c|c|c|c|c|c|}
\hline Abscissa. & $\begin{array}{r}\text { Ordinate } \\
\text { curve of } \\
\text { difference. }\end{array}$ & $\begin{array}{l}\text { Ordinate } \\
\text { curze of } \\
\text { error. }\end{array}$ & Abscissa. & $\begin{array}{l}\text { Ordinate } \\
\text { curve of } \\
\text { difference. }\end{array}$ & $\begin{array}{l}\text { Ordinate } \\
\text { ourve of } \\
\text { error. }\end{array}$ \\
\hline $\begin{array}{r}\cdot 0 \\
\cdot 1 \\
\cdot 2 \\
\cdot 3 \\
\cdot 4 \\
\cdot 5 \\
\cdot 6 \\
\cdot 7 \\
\cdot 8 \\
-9 \\
1 \cdot 0 \\
1 \cdot 1 \\
1 \cdot 2\end{array}$ & $\begin{array}{r}1 \cdot 28 \\
1 \cdot 28 \\
1 \cdot 25 \\
1 \cdot 14 \\
\cdot 99 \\
\cdot 86 \\
\cdot 70 \\
\cdot 58 \\
\cdot 47 \\
\cdot 37 \\
\cdot 30 \\
.24 \\
\cdot 19\end{array}$ & $\begin{array}{r}1.30 \\
1.28 \\
1.23 \\
1 \cdot 15 \\
1.05 \\
.93 \\
.81 \\
.68 \\
.56 \\
.45 \\
.35 \\
\cdot 26 \\
\cdot 19\end{array}$ & $\begin{array}{l}1 \cdot 3 \\
1.4 \\
1 \cdot 5 \\
1.6 \\
1 \cdot 7 \\
1 \cdot 8 \\
1.9 \\
2 \cdot 0 \\
2 \cdot 5 \\
3 \cdot 0 \\
3 \cdot 5 \\
4 \cdot 0\end{array}$ & $\begin{array}{l}\cdot 14 \\
\cdot 11 \\
.10 \\
.08 \\
.06 \\
.06 \\
.05 \\
.04 \\
.02 \\
.01 \\
.01 \\
.00\end{array}$ & $\begin{array}{l}\cdot 14 \\
\cdot 10 \\
.07 \\
.04 \\
.03 \\
.02 \\
.01 \\
.01 \\
.00 \\
.00 \\
.00 \\
.00\end{array}$ \\
\hline
\end{tabular}

With the spectrum of the water-bands we may now compare any other spectrum we please that lies between the extreme lines of the water-bands. We must expect to find the number 
of differences between certain limits equal to the area of our curve of difference between the same limits multiplied by the number of lines of the second spectrum. And if a curve is plotted in the manner indicated by Love, it evidently must resemble the curve given by the law of error, whatever the second spectrum may be. In this case, therefore, the method of Love cannot give us any information whether the coincidences between the lines of the two spectra are real or accidental. But we may derive some information by considering the value of the constant in the formula giren by the law of error. Supposing the coincidences to be real ones, the differences between the lines compared must be distributed according to the formula $y=\frac{2 c}{\sqrt{\pi}} e^{-c^{2} x^{2}}$. If now we can make an estimate of $c$ and find it considerably larger than $1 \cdot 148$, the distribution of differences ought to show a divergence from the distribution given above. If the divergence is not shown, the coincidences must be accidental. Only when $c$ is not found considerably larger than $1 \cdot 148$ we are left without an answer. The distribution of differences would then be the one given above, and would afford no reason to think the coincidences real ones.

The most important verification of A. Grünwald's farreaching speculations on the composition of the elements he believes to be afforded by the agreement between the wave-lengths of the lines in the spectrum of water, as deduced by him from those of the hydrogen spectrum, and their values as obtained by observation. But I find that the distribution of differences is in perfect accordance with the one expected for an equal number of wave-lengths chosen at random. To show this more clearly, I have taken the mantissas of $\log$ sin from $9^{\circ} 43^{\prime}$ to $12^{\circ} 4^{\prime}$, and of $\log$ tan from $19^{\circ} 20^{\prime}$ to $19^{\circ} 38^{\prime}$ for each minute abbreviated to five figures. These numbers lie between the extreme wavelengths of the water-bands. The distribution of differences between each of these numbers and the nearest wave-length of the water-spectrum does not show any serious divergence from the distribution corresponding to the wave-lengths calculated according to Grünwald's theory by multiplying the wave-lengths of hydrogen by $\frac{1}{2} *$.

The first column of the following table contains the limits

* I have taken Hasselberg's measurements, Mém. de l'Acad. de St. Pétersbourg, 1882, as Grinwald has preferred these to the more complete mensurements of 1883. I have abbreviated the halves to five figures, adding a unity to the fifth figure when it was even. 
of the differences, the second gives the expected number of differences within these limits, the third the observed number corresponding to the wave-lengths calculated from hydrogen, the fourth the observed number corresponding to the said mantissas of $\log$ sin and $\log$ tanl.

\begin{tabular}{|c|c|c|c|c|c|c|c|}
\hline $\begin{array}{l}\text { Limits of } \\
\text { differences. }\end{array}$ & $\begin{array}{l}\text { Expected } \\
\text { numbers. }\end{array}$ & \multicolumn{2}{|c|}{$\begin{array}{l}\text { Observed } \\
\text { numbers. }\end{array}$} & $\begin{array}{l}\text { Limits of } \\
\text { differences. }\end{array}$ & $\begin{array}{l}\text { Expected } \\
\text { numbers. }\end{array}$ & \multicolumn{2}{|c|}{$\begin{array}{l}\text { Observed } \\
\text { numbers. }\end{array}$} \\
\hline .00 to .05 & $10 \cdot 4$ & 12 & 6 & $2 \cdot 05$ to $2 \cdot 15$ & 0.6 & 2 & 1 \\
\hline$\cdot 05, \quad \cdot 15$ & $20 \cdot 6$ & 16 & 26 & $2 \cdot 15,225$ & 0.5 & & \\
\hline$\cdot 15 " .25$ & $20 \cdot 2$ & 19 & 16 & $2 \cdot 25 " 235$ & 0.4 & & \\
\hline $.25,35$ & $18 \cdot 4$ & 21 & 16 & 235,245 & & & \\
\hline$-35, " 45$ & 160 & 19 & 15 & $2.45,2.55$ & 0.9 & 1 & \\
\hline$\cdot 45, \quad \cdot 55$ & $13 \cdot 8$ & 16 & 16 & $2 \cdot 55,, 265$ & & & \\
\hline$\cdot 55,-65$ & $11 \cdot 3$ & 11 & 12 & 265,275 & & 1 & \\
\hline$\cdot 65,75$ & $9 \cdot 3$ & 8 & 9 & $275 \% 2 \cdot 85$ & 0.7 & & \\
\hline $.75 "-85$ & $7 \cdot 5$ & 7 & 11 & $285 ” 295$ & & & \\
\hline $85, .95$ & $5 \cdot 9$ & 5 & 12 & $2.95,3.05$ & & 1 & \\
\hline $.95 " 105$ & 4.9 & 6 & 1 & $3 \cdot 05,3 \cdot 15$ & 0.6 & 1 & 1 \\
\hline $1.05, \ldots 1 \cdot 15$ & $3 \cdot 8$ & 1 & 5 & $3 \cdot 15,3 \cdot 25$ & & & \\
\hline $1.15,1.25$ & $3 \cdot 1$ & & 2 & $3 \cdot 25,3.35$ & & 1 & \\
\hline $1.25,1.35$ & $2 \cdot 2$ & 3 & 3 & $3.35,3.45$ & $0 \cdot 4$ & & \\
\hline $1.35,1 \times 45$ & $1 \cdot 8$ & 1 & 2 & $3.45,3.55$ & & & \\
\hline $1.45,1.55$ & $1 \cdot 6$ & 3 & 2 & $3.55 \% 365$ & & & \\
\hline $1.55,165$ & $1 \cdot 1$ & $\ldots$ & & 365,375 & $0 \cdot 4$ & & \\
\hline $165,, 1 \cdot 75$ & $1 \cdot 0$ & . & 1 & 375,385 & & & \\
\hline 175,1855 & 0.9 & 2 & 2 & $3.85 \% 5 \cdot 25$ & 1.0 & 1 & 1 \\
\hline $1.85,1.95$ & 07 & & & $5.25 \% 675$ & $0 \cdot 7$ & 1 & \\
\hline $1.95,2.05$ & 0.7 & 2 & 1 & & & & \\
\hline
\end{tabular}

As the distribution of the differences corresponding to the wave-lengths calculated from hydrogen is in accordance with the expected distribution, it follows either that the coincidences are accidental or that their probable error is not smaller than the one corresponding to $c=1 \cdot 148$. The probable error for $c=1 \cdot 148$ is 0.42 . That is to say, $0.42 \times 10^{-7}$ millim., as $10^{-7}$ millim. is the unit of the wave-lengths. It seems to me not impossible that the probable error of the difference between Liveing and Dewar's measurements and the halves of Hasselberg's is as much as 0.42 . One cannot therefore, without more exact measurements, safely infer that Grünwald's coincidences are accidental. However, one can say that the distribution of differences gives no more reason to believe the coincidences real than to believe in a connexion between the mantissas of $\log \sin$ and the spectrum of water. 